\title{
PERSEPSI GURU TENTANG REWARD AND PUNISHMENT DAN IMPLEMENTASINYA DALAM PEMBELAJARAN DI MAN II MODEL MEDAN
}

\author{
Candra Wijaya \\ Universtas Islam Negeri Sumatra Utara Medan \\ Email: Candrawijaya@uinsu.ac.id \\ M. Luthfie Ramadhani \\ Universtas Islam Negeri Sumatra Utara Medan \\ Email: badloeth@gmail.com \\ Edi Jatmiko \\ Universtas Islam Negeri Sumatra Utara Medan \\ Email: edijatmiko31@gmail.com
}

\section{Naskah Diterima: 31-12-2019 Direvisi: 09-02-2020 Disetujui: 16-02-2020}

\begin{abstract}
Abstrak
Dalam kehidupan sehari-hari, kita sering menjumpai anak dengan karakter yang beragam. Ada anak yang mudah dibina dan ada yang sulit dibina, sebagian giat belajar dan sebagian lain sangat malas belajar, sebagian mereka belajar untuk maju dan sebagian lain belajar hanya untuk terhindar dari hukuman. Sebenarnya sifat-sifat buruk yang timbul dalam diri anak di atas bukanlah lahir dan fitrah mereka. Sifat-sifat tersebut timbul karena kurangnya peringatan sejak dini dari orang tua dan para pendidik. Maka merupakan kesalahan besar apabila kita menyepelekan kesalahan-kesalahan kecil yang dilakukan anak. Sebenarnya, tidak ada pendidik yang menghendaki digunakannya hukuman dalam pendidikan kecuali bila terpaksa. Hadiah atau pujian jauh lebih dipentingkan dari pada hukuman. Dalam dunia pendidikan, metode ini disebut dengan metode hadiah (reward) dan hukuman (punishement). Dengan metode tersebut diharapkan agar anak didik dapat termotivasi untuk melakukan perbuatan progresif. Penelitian ini bertujuan untuk mendeskripsikan dan menganalisis persepsi guru tentang reward and punishment dan implementasinya dalam pembelajaran di MAN 2 Model Medan.
\end{abstract}

Kata Kunci: Persepsi Guru, Hadiah, Hukuman, Pembelajaran

\begin{abstract}
In everyday life, we often encounter children with diverse characters. There are children who are easy to foster and some who are difficult to foster, some are keen to learn and some are very lazy to learn, some of them learn to progress and some of them learn just to avoid punishment. Actually the bad qualities that arise in the children above are not born and their nature. These traits arise due to the lack of early warning from parents and educators. So it is a big mistake if we underestimate the small mistakes made by children. In fact, there are no educators who want punishment to be used in education unless forced to. Gifts or compliments are far more important than punishment. In the world of education, this method is called the reward and punishement methods. With this method it is hoped that students can be motivated to do progressive deeds. This study aims to describe and analyze teacher perceptions about reward and punishment and its implementation in learning in MAN 2 Medan Model.
\end{abstract}

Keywords: Teacher Perception, Reward, Punshment. Learning 
Persepsi Guru Tentang Reward and Punisment,..

\section{PENDAHULUAN}

Allah Swt. menginstruksikan, setiap manusia mempunyai tujuan, ke sanalah Ia mengarahkannya, maka berlombalah kamu mengejar kebaikan. Di manapun kamu berada, Allah akan menghimpun kamu karena Allah berkuasa atas segalanya (QS.al-Baqarah: 148) dan untuk kamu masing-masing Kami tentukan suatu Undang-Undang dan jalan yang terang. Sekiranya Allah menghendaki niscaya Ia menjadikan kamu suatu umat, tetapi Ia hendak menguji kamu atas pemberian-Nya. Maka berlombalah kamu dalam kebaikan (QS Al-Maidah: 48). Manifestasi Ilahi ini mengisyaratkan adanya kompetensi yang harus dijalankan manusia menuju kebaikan pribadi dan sosial. Hidup kompetitif adalah sesuatu yang niscaya dalam pluralitas manusia yang menaik dan sengaja dinaikkan ${ }^{1}$. Hidup kompetitif ini akan senantiasa ditemui oleh manusia dalam keadaan bagaimanapun, pada saat kapanpun, dan ditempat mana pun. Tentu kompetisi itu harus mengacu kepada undang-undang (syir'ah) dan metode/jalan (manhaj) konsensus bersama dalam kebaikan ${ }^{2}$. Hidup kompetitif menuju kebaikan pribadi dan sosial yang sesuai dengan undang-undang memerlukan suatu metode atau jalan salah satunya adalah dengan berlaku disiplin, disiplin dalam hidup dan kehidupan ${ }^{3}$.

Penanaman disiplin akan peraturan ini tentunya ada pengawasan, ada reward dan ada funishment. ${ }^{4}$ Pemberian pahala (reward) bagi manusia unggul dalam konteks pendidikan kiranya memperoleh pembenaran teologis (theologis justivication) ${ }^{5}$. Agama Islam sendiri mengandung konsep pahala dan dosa untuk mengukur kualitas hidup manusia beriman ${ }^{6}$. Konsep reward dan punishment merupakan pengukuran pendidikan bagi kualitas fungsional edukatif siswa yang berprestasi dan bermasalah ${ }^{7}$. Hadiah, penghargaan, dan cenderamata adalah urgen diberikan

${ }^{1}$ W. James, The V arieties of Religious Experience: A Study in Human Nature: Being the Gifford Lectures on Natural Religion Delivered at Edinburgh in 1901-1902 (Creative Media Partners, LLC, 2018).

2 Said Aqil Husin Al Munawar dan Abdul Halim, Fikih bubungan antar agama (Jakarta: Ciputat Press, 2003).

3 Yeni Yusnita dkk., "The Effect of Professional Education and Training for Teachers (PLPG) in Improving Pedagogic Competence and Teacher Performance," Tadris: Jurnal Keguruan dan Ilmu Tarbiyah 3, no. 2 (28 Desember 2018): 123-30, https://doi.org/10.24042/tadris.v3i2.2701; Brian Leavy, "Effective leadership today - character not just competence," Strategy \& Leadership 44, no. 1 (11 Januari 2016): 20-29, https://doi.org/10.1108/SL-11-2015-0081.

4 Muhammad Husnur Rofiq, "Kedisiplinan Siswa Melalui Hukuman Dalam Perspektif Stakeholder Pendidikan," Nidhomul Haq: Jurnal Manajemen Pendidikan Islam 2, no. 2 (2017): 82-94, https://doi.org/10.31538/ndh.v2i2.25.

${ }^{5}$ Muhammad Anas Ma arif dan Ari Kartiko, "Fenomenologi Hukuman di Pesantren : Analisis Tata Tertib Santri Pondok Pesantren Daruttaqwa Gresik," Nadwa 12, no. 1 (22 Juni 2018): 181-96, https://doi.org/10.21580/nw.2018.12.1.1862.

6 Muhammad Anas Ma`arif, "Analisis Strategi Pendidikan Karakter Melalui Hukuman Preventif," Ta'allum: Jurnal Pendidikan Islam 6, no. 1 (6 Maret 2018): 31-56, https://doi.org/10.21274/taalum.2018.6.1.31-56.

7 Ahmadreza Fatahian Kelishadroky dkk., "The Role of Reward and Punishment in Learning," International Journal of Advanced Biotechnology and Research 7, no. special issue (1 Maret 2016): 780-88; Sri Sarjana, "Education Reward for Teacher: Implementation Strategy to Improve Teacher' Performance," TARBIYA: 
Candra Wijaya Dkk,

kepada mereka yang berprestasi. Sebaliknya, hukuman sebagai vaksinasi dini dalam konteks pendidikanpun layak diberikan kepada mereka yang bermasalah. ${ }^{8}$

Reward and Punishment sangat penting untuk diterapkan mengingat penelitian sebelumnya mengatakan bahwa hukuman mampu memberikan efek jera bagi pelakunya sedangkan hadiah mampu memberikan stimulus positif ${ }^{10}$. Walaupun banyak yang mendukung peenerapan hukuman dan hadiah akan tetapi beberapa hasil penelitian juga tidak menganjurkan penerapan hukuman dan lebih pada penerapan hadiah saja ${ }^{11}$. Hukuman juga mampu memberikan ketakutan bagi peserta didik sehingga pelanggaran lebih dapat diminimalisir dan hukuman mampu membentuk ana lebih disiplin ${ }^{12}$. Terkait kontradiksi penerapan metode reward and punishment dalam pendidikan maka peneiliti tertarik untuk meneliti Madrasah Aliyah Negeri II Medan.

\section{Kajian Literatur}

\section{Pengertian Ganjaran (Reward)}

Reward dalam kamus bahasa Inggris mempunyai arti ganjaran, hadiah. ${ }^{13}$ Dalam bahasa arab, hadiah berasal dari kata "هدية ج هدايا" yang berarti hadiah atau pemberian. ${ }^{14}$ Dalam Kamus Besar Bahasa Indonesia sendiri disebutkan bahwa ganjaran adalah hadiah atau upah (sebagai pembalas jasa, perbuatan baik, dsb) ${ }^{15}$.

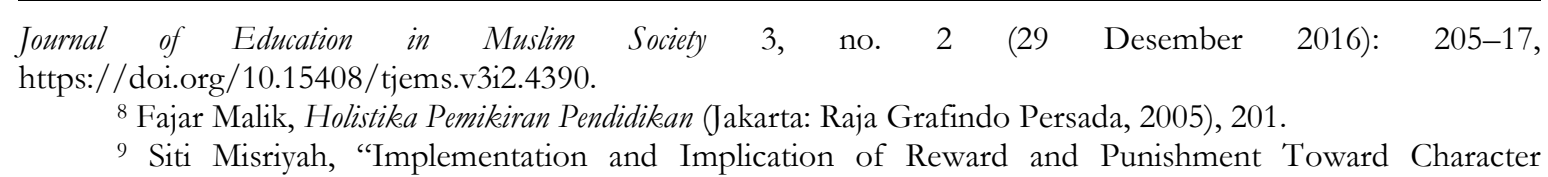
Education at Senior High School in Pemalang," Hikmatuna: Journal for Integrative Islamic Studies 1, no. 1 (2015), http://e-journal.stain-pekalongan.ac.id/index.php/hikmatuna/article/view/473; Muhammad Anas Ma'arif, "Hukuman (Punishment) Dalam Perspektif Pendidikan Di Pesantren," Ta'allum: Jurnal Pendidikan Islam 5, no. 1 (1 Juni 2017): 1-20, https://doi.org/10.21274/taalum.2017.5.1.1-20.

10 Sarjana, "Education Reward for Teacher."

${ }^{11}$ Ma arif dan Kartiko, "Fenomenologi Hukuman di Pesantren."

12 Abdullah Idi dan Ahmad Jamin, "Penerapan Non-Corporal Punishment di Madrasah Aliyah: Studi Kasus di MAN 1 Sungai Penuh dan MAN Kemantan," 2018; Hasan Baharun, "Penerapan pembelajaran active learning untuk meningkatkan hasil belajar siswa di madrasah," PEDAGOGIK: Jurnal Pendidikan 1, no. 1 (2015); Annisa Novitasari, "Pemberian Reward and Punishment Dalam Membentuk Karakter Disiplin Anak Pada Sekolah Madrasah Ibtidaiyah," Halaqa: Islamic Education Journal 3, no. 1 (25 Mei 2019): 27-33-33, https://doi.org/10.21070/halaqa.v3i1.2113; Rusmilawati Windari, "Penggunaan Hukum Disiplin (Corporal Punishment) pada Anak Di Lingkungan Sekolah Dalam Perspektif Hukum Pidana di Indonesia," Jurnal Hukum PRIORIS 4, no. 3 (18 Mei 2016): 303-28; Johanes Purwanto Purwanto, "Upaya Meningkatkan Disiplin Guru Dalam Kehadiran Mengajar Di Kelas Melalui Reward and Punishment Di Sdn Bandulan 1 Kecamatan Sukun Malang," Jurnal Bidang Pendidikan Dasar 1, no. 2 (10 Juni 2017): 58-69, https://doi.org/10.21067/jbpd.v1i2.1903. 1975), 485

${ }_{13}$ John M. Echols dan Hassan Shadily, An English-Indonesian Dictionary (Ithaca: Cornell University Press,

${ }_{14}$ M. Yunus, Kamus Arab-Indonesia (Jakarta: Yayasan Penyelenggara Penterjemah Pentafsiran Al-Quran, 1973), 480, https://books.google.co.id/books?id=ifaNngEACAAJ.

15 Indonesien dan Pusat Bahasa (Indonesia), ed., Kamus besar bahasa Indonesia Pusat Bahasa: Edisi Keempat, Cetakan ketujuh Edisi 4 (Jakarta: Gramedia Pustaka Utama, 2013), 333. 
Persepsi Guru Tentang Reward and Punisment,..

John W. Santrock menemukakan penguatan (reward) adalah konsekuensi yang meningkatkan probabilitas bahwa suatu perilaku akan terjadi. Penguatan berarti memperkuat, dalam penguatan positif frekuensi respons meningkat karena diikuti dengan stimulus yang mendukung (rewarding), sedang dalam penguatan negatif, frekuensi respons meningkat karena diikuti dengan penghilangan stimulus yang merugikan atau tidak menyenangkan. Contoh ayah mengomel anaknya agar mengerjakan PR secara terus menerus, sehingga anaknya merasa lelah dengan omelan dan mengerjakan pekerjaan rumahnya ${ }^{16}$.

Abdurrahman Mas'ud mendefinisikan reward adalah suatu pemberian penghargaan dalam arti luas dan fleksibel karena prestasi seseorang. ${ }^{17}$ Sementara itu Ngalim Purwanto menerangkan, hadiah (reward) merupakan alat pendidikan yang dapat membuat hati menjadi senang dan tenang dan diberikan kepada anak yang memiliki prestasi atau keberhasilan tertentu dalam pendidikan, memiliki kemajuan dan tingkah laku yang baik sehingga dapat dijadikan contoh bagi teman-temannya. ${ }^{18}$ Al-Baqi sendiri menjelaskan bahwa kata hadiah di dalam al-Qur'an biasanya disebutkan dalam berbagai bentuk uslub, di antaranya ada yang menggunakan kata 'ajr (أجر) dan tsawab (نواب), seperti dalam Q.S al-Baqarah ayat 62, al'Ankabut ayat 58, dan al-Bayyinah ayat $8 .{ }^{19}$

\section{Bentuk-bentuk Ganjaran dalam Pendidikan Islam}

Untuk menentukan hadiah apakah ynag layak dan baik diberikan kepada anak merupakan sesuatu hal yang sangat sulit. Karena hadiah sebagai alat pendidikan banyak sekali macamnya, hadiah pada dasarnya dapat berupa materi dan non materi, yang berupa materi seperti barang atau benda dan yang non materi tentunya lebih banyak lagi seperti pujian, perhatian, penghargaan dan lain sebagainya.

Macam Hadiah 1) Pujian yang baik (memberi kata-kata yang menggembirakan) 2) Berdoa 3) Menepuk pundak 4) Memberi pesan 5) Menjadi pendengar yang baik 6) Mencium buah hati dengan penuh cinta dan kasih sayang ${ }^{20}$ 7) Hadiah dapat juga berupa benda yang menyenangkan dan berguna bagi anak-anak seperti: pensil, buku tulis, makanan ringan, permainan dan lain sebagainya. ${ }^{21}$

${ }^{16}$ Santrock John W, Psikologi Pendidikan, trans. oleh Tri Wibowo BS, 6 ed. (Jakarta: Prenada Media Grup, 2015), 272-73.

17 Abdurrachman Mas'ud, Menggagas format pendidikan nondikotomik: humanisme religius sebagai paradigma pendidikan Islam (Gama Media, 2002), 172.

18 Purwanto Ngalim, Ilmu Pendidikan Teoritis dan Praktis, 17 ed. (Bandung: Remaja Rosdakarya, 2006), 182.

${ }^{19}$ Fuad Abdul Baqi’, Mu jam al-Muafarras, 2 ed. (Beirut Lebanon: Dar al-Kotob Al-Ilmiyah, 2010), $205-6$.

${ }^{20}$ Nahlawi Abdurrahman, Ushul al Tarbiyah al-Islamiyah fi al-Baiti wal al Madrasah wal al-Mujtama, trans. oleh Shihavuddin (Jakarta: Gunan Insani, 1995).

${ }^{21}$ Ngalim, Ilmu Pendidikan, 183. 
Sementara itu, Al Rasyidin menerangkan, Al-Quran menginformasikan bahwa Allah Swt memberikan ganjaran kepada hamba-hamba-Nya dalam dua bentuk, yaitu ganjaran yang berbentuk fisik atau material dan non fisik. bentuk bentuk ganjaran yang bersifat fisik atau material selalu dideskripsikan dalam bentuk makanan, minuman, buah-buahan, binatang ternak, air hujan yang diturunkan dari langit yang bermanfaat bagi menghidupkan tanah dan menyuburkan tumbuhan, dan laim-lain. Sementara itu dalam bentuk non fisik, al-Quran selalu menggambarkan ganjaran dalam bentuk ketenangan atau ketentraman bathin, keteguhan pendirian dalam berbuat kebaikan (istiqamah), hidayah Allah swt, pahala di akhirat, surga dan berbagai kenikmatan di dalamnya, dan lain-lain.

Berdasarkan informasi al-Quran sebagaimana dipaparkan di atas, maka dalam konteks pendidikan Islami, bentuk ganjaran juga dapat diklasifikasikan menjadi dua macam, yaitu ${ }^{22}$ :

Ganjaran fisik yaitu perlakuan menyenangkan yang diterima seseorang dalam bentuk fisik atau material sebagai konsekuensi logis dan perbuatan baik ('amal al-shalib) atau prestasi terbaik yang berhasil ditampilkan atau diraihnya. Misalnya: pemberian hadiah, cendramata, atau pemberian penghargaan baik berupa piala, buku atau kitab, beasiswa, dan lain sebagainya. Ganjaran non fisik dalam bentuk non fisik yaitu perlakuan menyenangkan yangditerima seseorang dalambentuk non fisik sebagai konsekuensi logis dariperbuatan baik ('amal al-shalib) atauprestasi terbaik yang berhasil ditampilkan atau diraihnya.

Dalam perspektif Islam, manusia adalah makhluk dwi dimensi yang merupakan resultan dari dimensi fisik (jism) dan non fisik (ruh). Manusia yang sempurna adalah manusia yang mampu memenuhi kebutuhan fisik dan non fisiknya secara seimbang. Karena itu dalam kehidupannya di dunia ini, setiap manusia senantiasa berupaya meraih kesenangan atau kebahagiaan, baik dalam arti fisik maupun non fisik.

Dalam tataran operasional, bentuk-bentuk ganjaran yang bersifat fisik itu bisa diberikan para pendidik dalam bentuk pemberian hadiah, cendramata, atau penghargaan baik berupa piala, buku atau kitab, dana tabungan, dana beasiswa, piagam penghargaan, membawa peserta didik darmawisata, dan lain-lain. Sedangan untuk ganjaran yang bersifat non fisik dapat diberikan dalam bentuk pujian atau sentuhan verbal, sentuhan fisik seperti mengacungkan jempol, ucapan terima kasih, senyuman, dan berbagai penguatan positif lainnya (positive reinforcements). ${ }^{23}$

\section{Dasar-dasar Pertimbangan Pemberian Ganjaran}

\footnotetext{
22 Misriyah, "Implementation and Implication of Reward and Punishment Toward Character Education at Senior High School in Pemalang."

${ }^{23}$ Al Rasyidin, Falsafah Pendidikan Islami (Perdana Publishing, 2008), 95.
} 
Persepsi Guru Tentang Reward and Punisment,..

Al Rasyidin mengemukakan tujuan terpenting dari pemberian ganjaran dalam pendidikan adalah memotivasi peserta didik agar bersemangat dan memiliki sense of competition untuk senantiasa menampilkan prilaku positif atau prestasi terbaik yang memungkinkan untuk diraihnya. Meskipun hampir semua pakar dan pendidik muslim sepakat penggunaan pemberian ganjaran dalam pendidikan, namun mereka memperingatkan agar para pendidik bersikap hati-hati dalam implementasinya. Sebab, bila tidak hati-hati pemberian ganjaran itu justru bisa kontra produktif atau tidak tepat sasaran sesuai tujuannya. Dalam konteks ini, Abdur Rahman Shalih Abdullah bahkan mengharuskan agar setiap pendidik terlebih dahulu mencapai predikat 'alim sebelum mereka memberikan ganjaran kepada peserta didiknya. Hal tersebut dimaksudkan agar ganjaran yang diberikan benar-benar bernilai guna bagi para peserta didik. Sebab, peserta didik akan tersentuh jiwanya manakala ganjaran tersebutu dianugrahkan oleh seorang pendidik ang berkarakter mulia.

Dalam tataran praktikal, agar ganjaran bermanfaat atau bernilai edukatif, maka pemberian ganjaran kepada peserta didik perlu memperhatikan beberapa hal berikut: 1) Berikan ganjaran atas perbuatan atau prestasi yang dicapai peserta didik, bukan atas dasar pribadinya. 2) Dalam konteks ini, para pendidik harus menegaskan bahwa ganjaran itu diberikan kepada meraka dikarenaka perilaku positif atau prestasi terbaik yang berhasil diraihnya. 3) Berikan penghargaan yang sesuai atau proporsional dengan prilaku atau prestasi yang diraih peserta didik. Sampaikan penghargaan untuk hal-hal yang positif, tetapi jangan terlalu sering. 4) Jangan memberikan penghargaan disertai dengan ungkapan membanding bandingkan seorang peserta didik dengan orang lain. 5) Pilihlah bentuk penghargaan yang sesuai dengan kebutuhan pesertadidik. ${ }^{24}$

\section{Hukuman (Punishment)}

Punishment dalam bahasa Inggris artinya adalah hukuman atau siksaan. ${ }^{25}$ Dalam bahasa arab hukuman berasal dari kata "عقاب ج عقوبة" yang berarti siksa. ${ }^{26}$ Dalam Kamus Besar Bahasa Indonesia, hukuman adalah sanksi atau siksa (terhadap orang yang melanggar suatu aturan). ${ }^{27}$ Susana dkk menerangkan hakikat hukuman berupa sanksi fisik maupun psikis atas pelanggaran atau kesalahan yang dilakukan anak. Hukuman juga mengajarkan anak tentang apa yang tidak boleh dilakukan, bukan apa yang harus dilakukan di masa yang akan datang. ${ }^{28}$

\footnotetext{
${ }^{24}$ Rasyidin, 96.

${ }^{25}$ Echols dan Shadily, An English-Indonesian Dictionary, 456.

${ }^{26}$ Yunus, Kamus Arab-Indonesia.

${ }^{27}$ Indonesien dan Pusat Bahasa (Indonesia), Kamus besar bahasa Indonesia Pusat Bahasa.

${ }^{28}$ Tjipta Susana, Familia, dan Tim Pustaka, Mempertimbangan Hukuman Pada Anak (Jogjakarta: Kanisius,
} 2007), 99. 
Candra Wijaya Dkk,

Punishment banyak digunakan beberapa orangtua maupun guru ketika mendidik anak ataupun siswa. Beberapa orangtua terkadang memberi hukuman seperti, memotong uang saku, memukul anak dan hukuman-hukuman lainya yang membuat anak merasa kesakitan baik fisik maupun psikis. ${ }^{29}$

Punishment dalam istilah psikologi, terjadi tatkala muncul situasi deprivation (kehilangan) atau pengalaman tidak enak yang ditimbulkan oleh satu kelompok atau individu secara sengaja dengan merugikan kelompok lain yang disebabkan oleh misdeed, pelanggaran atau kejahatan oleh kelompok pertama ${ }^{30}$. Hukuman (punishment) dalam pendidikan menurut Ahmad tafsir memiliki pengertian yang luas, mulai dari hukuman ringan sampai pada hukuman berat, sejak kerlingan yang menyengat sampai pukulan yang agak menyakitkan. Sebenarnya, tidak ada ahli pendidikan yang menghendaki digunakanya hukuman dalam pendidikan kecuali bila terpaksa. Hadiah atau pujian jauh lebih dipentingkan ketimbang hukuman. ${ }^{31}$

\section{Bentuk-bentuk Hukuman dalam Pendidikan Islam}

Al Rasyidin mengemukakan hukuman secara umum sama halnya dengan ganjaran, hukuman juga diklasifikasikan ke dalam dua bentuk, yaitu:

\section{Hukuman fisik}

Dalam al-Quran, hukuman yang berbentuk fisik bisa berupa dipukul (dharaba) dicambuk (jild), dipotong tangan (qath), dibunuh (qat), didenda (diyat), dan dipenjarakan atau diisolasi (tajir). Hukuman fisik yaitu perlakuan kurang atau tidak menyenangkan yang diterima seseorang dalam bentuk fisik atau material sebagai konsekuensi logis dari perbuatan tidak baik ('amal as-syaiat) aatau prestasi buruk yang ditampilkan atau diraihnya.

\section{Hukuman non fisik}

Hukuman non fisik bisa berupa dihinakan Allah swt hidupnya di dunia, tidak ditegur Allah swt di akhirat, diterpa kegelisahan batin, dosa, siksa neraka, dan lain sebagainya. Hukuman non fisik yaitu perlakuan kurang atau tidak menyenangkan yang diterima seseorang dalam bentuk non fisik sebagai konsekuensi logis dari perbuatan tidak baik ('amal as-syaiat) aatau prestasi buruk yang ditampilkan atau diraihnya.

Dalam tataran praktikal, implementasi ganjaran yang bersifat fisik bisa diberikan para penddidik dalam bentuk memukul, mewajibkannya melakukan tugas-tugas fisik seperti membersihkan ruangan atau kamar mandi, berdiri di depan kelas, mengeluarkan atau

${ }^{29}$ Ngalim, Ilmu Pendidikan, 171.

30 Mas'ud, Menggagas format pendidikan nondikotomik, 171.

31 Ahmad Tafsir, Ilmu pendidikan Islami, Cet. 1 (Bandung: Remaja Rosdakarya, 2012), 186. 
Persepsi Guru Tentang Reward and Punisment,..

mengisolasinya dari dalam kelas, mewajibkannya membayar denda, dan lain-lain. sedangkan untuk hukuman yang bersifat non fisik antara lain dapat diberikan dalam bentuk memarahinya, meberi peringatan disertai ancaman, dan lain sebagainya. ${ }^{32}$

\section{Dasar-dasar Pertimbangan Pemberian Hukuman}

Punishment

Hukuman pada dasarnya merupakan akibat dari suatu perbuatan manusia itu sendiri, sebagaimana firman Allah swt dalam Q.S at-Taubah [9] ayat 74;

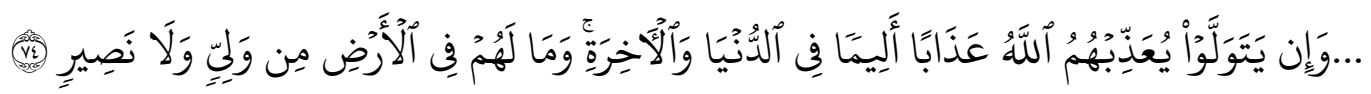

“...dan jika mereka berpaling, niscaya Allah akan mengazab mereka dengan azab yang pedih di dunia dan akhirat; dan mereka sekali-kali tidaklah mempunyai pelindung dan tidak (pula) penolong di muka bumi”.

Athiyah al-Abrasyi berpendapat bahwa:

$$
\text { ان الغرض منها في التربية الاسلام هو الارشاد والاصلاح لا الزجر والانتقام }
$$

"Maksud hukuman dalam pendidikan Islam ialah sebagai tuntutan dan perbaikan, bukan sebagai hardikan dan balas dendam." 33

Sedangkan di dalam hadist dijelaskan sebagai berikut:

$$
\begin{aligned}
& \text { عن عمر و ابن شعيب عن أبيه عن جده قال : قال رسول الله ص.م : مرو اولادكم بالصلاة وهم ابناء سبع }
\end{aligned}
$$

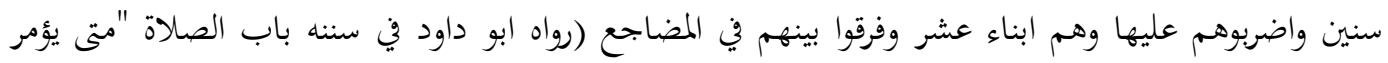

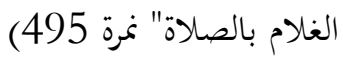

"Dari Amr bin Syu'aib dari ayahnya, dari kakeknya bahwa Rasulullah saw bersabda: "surublah anak-anak kalian mengerjakan shalat sejak mereka berusia tujuh tabun. Pukullah mereka jika melalaikannya ketika mereka berusia sepuluh tabun, dan pisabkan tempat tidur mereka". (HR. Abu Daud dalam kitabnya bab shalat "kapan anak diperintahkan sholat" hadist no. 49)

Makna dari kata (واضربو) dalam hadits tersebut adalah memberikan hukuman pukulan secara fisik, karena anak meninggalkan shalat. Di samping itu, pukulan yang diberikan harus mengenai badannya dan tidak boleh mengenai wajahnya. Oleh karena itu pukulan tersebut

32 Rasyidin, Falsafah Pendidikan Islami, 100.

33 Muhammad Athiya Abrasy, Dasar dasar Pendidikan Islam, trans. oleh Tasirun Sulaiman (Ponorogo: Pusat Studi Ilmu dan Amal, 1991), 115. 
Candra Wijaya Dkk,

harus diberikan kepada anak ketika sudah berumur 10 tahun, karena pada usia 10 tahun ke atas ini seorang anak sudah dianggap mempunyai tanggung jawab (baligh). ${ }^{34}$

Sementara itu Al Rasyidin dalam perspektif falsafah pendidikan Islami, hukuman pada dasarnya adalah instrument untuk: Pertama, memelihara fithrah peserta didik agar tetap suci, bersih dan bersyahadah kepada Allah Swt. Kedua, membina kepribadian pesrta didik agar tetap istiqamah dalam berbuat kebajikan (amal al-shalihat) dan berakhlak karimah dalam setiap perilaku atau tindakan. Ketiga, memperbaikai diri peserta didik dari berbagai sifat dan amal tidk terpuji (amal al-syai'at) yang telah dilakukannya.

Berdasarkan hal itu, maka para pakar pendidikan Islam sepakat bahwa hukuman tidak diperlukan manakala masih ada instrumen lain yang bisa digunakan untuk memelihara fitrah peserta didik agar tetap beriman atau bersyahadah kepada Allah swt. Hukuman baru diperlukan dan bisa dilaksanakan ketika diyakini bahwa hampir tidak ada lagi instrumen lain yang bisa digunakan untuk memelihara, membina atau menyadarkan anak didik dari kesalahan yang telah dilakukannya. Seorang pendidik harus memperhatikan beberapa kaedah berikut ini, yaitu:

1)Jangan sekali-kali menghukum sebelum pendidik berusaha sungguh-sungguh melatih, mendidik, dan membimbing anak didiknya dengan pengetahuan, keterampilan, dan sikap mental yang baik. 2) Hukuman tidak boleh dijalankan sebelum pendidik menginformasikan atau menjelaskan konsekuensi logis dari suatu perbuatan. 3) Anak tidak boleh dihukum sebelum pendidik memberikan peringatan pada mereka. 5) Tidak dibenarkan menghukum anak sebelum pendidik berusaha secara sungguh-sungguh membiasakan mereka dengan prilaku yang terpuji. 6) Hukuman belum boleh digunakan sebelum pendidik memberikan kesempatan pada anak didiknya untuk memperbaiki diri dari kesalahan yang telah dilakukannya. 7) Sebelum memutuskan untuk menghukum, pendidik hendaknya berupaya menggunakan mediator untuk menesehati atau merubah perilaku peserta didik. 8) Setelah semua hal diatas dipenuhi, maka seorang pendidik baru dibolehkan menghukum peserta didik dan itupun dengan beberapa catatan:

1) Jangan menghukum ketika marah.

2) Jangan menghukum karena ingin membalaskan dendam atau sakit hati.

3) Hukuman harus sesuai dengan tingkat kesalahan.

4) Hukumlah pesrta didik secara adil, jangan pilih kasih atau berat sebelah.

${ }^{34}$ Muhammad Syamsul Haq Abu Thayyib, A'unul Ma'bud, Syarah Sunan Abu Daud, vol. 2 (Lebanon: Dar al Fikri, 2006), 161. 
5) Jangan memberi hukuman yang dapat merendahkan harga diri atau martabatpeserta didik.

6) Jangan sampai melukai.

7) Pilihlah bentuk hukuman yang dapat mendorong peserta didikuntuk segeramenyedari dan memperbaiki keliruannya.

8) Mohonlah petunjuk Allah swt ${ }^{35}$.

\section{METODE PENELITIAN}

Penelitian ini menggunakan metode penelitian kualitatif dengan pendekatan fenomenologi. Menurut Moleong penelitian kualitatif adalah penelitian yang bermaksud untuk memahamai fenomena tentang apa yang dialami oleh subjek penelitian. ${ }^{36}$ Informan penelitian ini adalah kepala Madrasah Aliyah Negeri 2 Model Medan, Wakil Ketua Madrasah bagian Kesiswaan, Guru Bimbingan dan Konseling, guru kelas dan beberapa siswa. Teknik pengumpulan data dilakukan melalui wawancara mendalam, observasi, dan dokumentasi. Teknik analisis data dilakukan dengan cara mereduksi data, penyajian data dan penarikan kesimpulan atau verifikasi. Teknik penjamin keabsahan data dengan cara triangulasi data, transferabilitas dan konfirmabilitas.

\section{HASIL DAN PEMBAHASAN}

\section{Profil Madrasah Aliyah Negeri 2 Model Medan}

Madrasah Aliyah Negeri (MAN) 2 Medan sebelum bernama "MAN 2 Model” terlebih dahulu beroperasi melaksanakan program pendidikan dengan nama "PGAN", singkatan dari Pendidikan Guru Agama Negeri. PGAN merupakan institusi pendidikan agama Islam pertama didirikan oleh Kementerian Agama di Sumatera Utara. PGAN ini berdiri di Medan pada tahun 1957 berlokasi di Marindal dengan mempergunakan lokasi gedung pendidikan AlJam'iyatul Washliyah.

Pada masa awal berdiri PGAN, Kementerian Agama belum menyiapkan gedung belajar khusus untuk keperluan pendidikan itu. Kementerian Agama mengambil inisiatif untuk melakukan kontrak perjanjian tertulis guna menumpang kepada pihak pengelola Al-jam'iyatul Washliyah, dengan kesepakatan bahwa sebelum Kemenag mampu menyiapkan pendirian gedung belajar PGAN, maka Al-Jam'iyatul Washliyah memberikan hak pakai sementara, dan jika gedung PGAN berdiri, Kemenag harus mengembalikan hak milik itu sepenuhnya kepada Al-Jam'iyatul Washliyah.

\footnotetext{
35 Rasyidin, Falsafah Pendidikan Islami, 100-103.

36 Moloeng Lexy J, Metodologi penelitian Kualitatif, 29 ed. (Bandung: Rosdakarya, 2011), 6.
} 
Candra Wijaya Dkk,

Pada tahun 1992, Menteri Agama RI Munawir Sjazali mengeluarkan Keputusan Menag Nomor 42 Tahun 1992 tentang pengalihan PGAN menjadi MAN. Pada tahun itu pula PGA dinyatakan setara dengan SMA, seiring dengan Keputusan Mendikbud tentang pengalihan Sekolah Pendidikan Guru (SPG) menjadi Sekolah Menengah Atas (SMA). Selanjutnya pada tahun 1998, MAN 2 berubah nama dan dikukuhkan oleh Menteri Agama menjadi "MAN 2 Model”. Pengukuhan ini dilakukan untuk menjadikan MAN 2 sebagai MAN percontohan bagi seluruh Madrasah Aliyah di wilayah Sumatera Utara. Madrasah ini mendapat kepercayaan dari Kementerian Agama RI untuk dijadikan model tentu saja dilatarbelakangi oleh beberapa faktor, antara lain: letaknya yang strategis di tengah kota yang mudah dilalui oleh berbagai jenis alat transportasi darat, memiliki areal luas yang memungkinkan dilaksanakannya peningkatan sarana/fasilitas, kualitas guru yang ditandai dengan profesionalitas dan tingkat pendidikannya, keberhasilan para alumninya diterima pada perguruan tinggi favorit di luar Sumatera bahkan di luar negeri, keberhasilan daya jual alumninya untuk diterima bekerja pada kebanyakan instansi pemerintah maupun swasta, dan sebagainya. Banyak pihak menyambut positif upaya Kementerian Agama dalam menetapkan madrasah ini menjadi model, karena dinilai dapat meningkatkan citra MAN 2 di tengah publik yang sebelumnya sering dipandang sebagai lembaga pendidikan kelas dua (second class) setelah lembaga pendidikan menengah umum.

\section{Visi dan Misi}

Visi

Islami, Integritas, berprestasi dan cinta lingkungan.

Misi

Menyelenggarakan proses pembelajaran dan latihan berbasis pada akhlakul karimah dan prestasi

Menyelenggarakan proses pembelajaran dan latihan berkarakter Indonesia

Menyelenggarakan proses pembelajaran dan latihan yang bernuansa lingkungan

Menyelenggarakan proses pembelajaran dan latihan sistematis dan berteknologi

Menyelengarakan proses pembelajaran dan latihan berbasis penelitian dan pengembangan. 


\section{Pemberian Reward}

Pemberian reward di MAN 2 Model Medan ini lebih diapresiasikan guru terutama kepala madrasah kepada peserta didik yang berprestasi diluar madrasah menggunakan atribut madrasah $^{37}$. Sebagai contoh dalam beberapa kasus ajang perlombaan baik itu antar sekolah sekota Medan maupun se-provinsi Sumatera Utara. Hal ini menurut peneliti baik, akan tetapi alangkah baiknya pula apabila guru-guru khususnya kepala madrasah juga memberikan apresiasi kepada siswa di dalam madrasah yang senantiasa berprestasi dan disiplin dalam mentaati peraturan-peraturan madrasah serta senantiasa tidak bersikap hati-hati dan tidak pernah sama sekali melanggar peraturan yang telah ditetapkan madrasah. Ini akan menjadikan motivasi dan semangat bagi siswa-siswa lainnya agar tidak lalai dan melanggar peraturan madrasah.

Hanya saja banyak guru yang masih belum memahami akan definisi hukuman sehingga banyak yang menyalah gunakan hukuman. Walaupun banyak pakar membolehkan hukuman seperti Abdullah Nashih Ulwan, Malik Fadjar ${ }^{38}$ dan yang lainya akan guru juga perlu pemahhaman. Dalam hal ini peran kepala madrasah sangat diperlukan. Kepala madarasah memberikan arahan dan wawasan terkait hukuman yang harus diberikan. Penulis sepakat dengan Anas ${ }^{39}$ bahwa hukuman bleh diberikan dengan catatan sebagai alternatif saja ketika aturan yang pertama dan kedua tidak bisa di laksanakan.

\section{DISKUSI DATA}

Pemberian hukuman atau sanksi terhadap anak didik haruslah mempunyai tujuan baik, bukan karena ingin menyiksa atau balas dendam. Sebagaimana yang dikatakan oleh Athiyah alAbrasyi:

$$
\text { ان الغرض منها في التربية الاسلام هو الارشاد والاصلاح لا الزجر والانتقام }
$$

"Maksud hukuman dalam pendidikan Islam ialah sebagai tuntutan dan perbaikan, bukan sebagai hardikan dan balas dendam."

Pemberian hukuman guru terhadap anak didiknya di MAN 2 Model Medan ini menurut penulis sudah baik, karena hukuman yang diterapkan di madrasah ini sebatas hukuman yang tidak melibatkan kontak fisik secara langsung antar guru terhadap anak didiknya. Hal ini sesuai dengan apa yang telah dipaparkan oleh Al Rasyidin bahwa hukuman tidak diperlukan manakala masih ada instrumen lain yang bisa digunakan untuk memelihara

${ }^{37}$ Burhanddin, Wawancara, 2019.

38 'Abd Allah Nasih Ulwan dkk., Pendidikan Anak Dalam Islam, trans. oleh Jamaluddin Miri (Jakarta: Pustaka Amani, 2007); Malik, Holistika Pemikiran Pendidikan; Ngalim, Ilmu Pendidikan.

${ }^{39}$ Ma arif dan Kartiko, "Fenomenologi Hukuman di Pesantren." 
Candra Wijaya Dkk,

fitrah peserta didik agar tetap beriman atau bersyahadah kepada Allah swt. Hukuman baru diperlukan dan bisa dilaksanakan ketika diyakini bahwa hampir tidak ada lagi instrumen lain yang bisa digunakan untuk memelihara, membina atau menyadarkan anak didik dari kesalahan yang telah dilakukannya. Seorang pendidik harus memperhatikan beberapa kaedah berikut ini, yaitu:

Jangan sekali-kali menghukum sebelum pendidik berusaha sungguh-sungguh melatih, mendidik, dan membimbing anak didiknya dengan pengetahuan, keterampilan, dan sikap mental yang baik. Hukuman tidak boleh dijalankan sebelum pendidik menginformasikan atau menjelaskan konsekuensi logis dari suatu perbuatan. Anak tidak boleh dihukum sebelum pendidik memberikan peringatan pada mereka. Tidak dibenarkan menghukum anak sebelum pendidik berusaha secara sungguh-sungguh membiasakan mereka dengan prilaku yang terpuji.

Hukuman belum boleh digunakan sebelum pendidik memberikan kesempatan pada anak didiknya untuk memperbaiki diri dari kesalahan yang telah dilakukannya. Sebelum memutuskan untuk menghukum, pendidik hendaknya berupaya menggunakan mediator untuk menesehati atau merubah perilaku peserta didik.

Setelah semua hal diatas dipenuhi, maka seorang pendidik baru dibolehkan menghukum peserta didik dan itupun dengan beberapa catatan: Jangan menghukum ketika marah. Jangan menghukum karena ingin membalaskan dendam atau sakit hati. Hukuman harus sesuai dengan tingkat kesalahan. Hukumlah pesrta didik secara adil, jangan pilih kasih atau berat sebelah. Jangan memberi hukuman yang dapat merendahkan harga diri atau martabatpeserta didik. Jangan sampai melukai. Pilihlah bentuk hukuman yang dapat mendorong peserta didikuntuk segeramenyedari dan memperbaiki keliruannya. Mohonlah petunjuk Allah swt.

Senada dengan hal tersebut wawacara dengan Zuraidah ${ }^{40}$ guru bimbingn konseling bahwa pemberian hukuman dan ganjaran sangatlah penting meningat metode pendidikan ini sangatlah cocok untuk menekan kedisiplinan dan mengurangi kenakalan peserta didik. Ganjaran juga bisa memberikan motivasi untuk lebih giat lagi melakukan pekerjaan sekolah dan tugas yang diberikan guru hal ini seperti yang di paparkan oleh Nur Ariza "Reward dan punishment sangatlah penting agar peserta didik termotivasi dan merasa dihargai".

Perlu diketahui bahwa hukuman yang diterapkan oleh pendidik adalah hukuman yang mendidik seperti membaca Al-Qur`an, menghafal hadist, membersihkan pekarangan madrasah, memberihkan kelas, surat pemanggilan orang tua apabila dirasa sudah terlalu berlebian melakukan pelanggaran. Dal hal ini juga sudah masuk dalam buku tata tertib sekolah

40 Zuraidah, Wawancara, Guru Bimbinga Konseling, 2019. 
Persepsi Guru Tentang Reward and Punisment,..

tentang aturan hak dan kewajiban peserta didik. Setiap sekolah atau madrasah pastinya mempunyai aturan semacam ini dan ini juga sama seperti penelitian terdahulu bahwa hukuman yang mendidik memang perlu diberlakukan ${ }^{41}$.

Analisis peneliti bahwa jika hukuman dirasa perlu maka sepertinya lembaga atau guru bisa mengadopsi cara mendidik ramah Ibnu Khaldun ${ }^{42}$ bahwa anak sebenarnya adalah fitrah (suci) maka alangah baiknya hukuman harus dihindarkan sejak dini. Ibnu khaldun terkenal dengan pendidikan dengan kasih sayang. Sedangkan dalam dunia psikologi pendidikan (behavoisme) lebih mengutamakan penguatan positif (reinforcement). Hukuman hanya akan menekan sikap buruk anak dalam jangka dekat saja tidak secara permanen sehingga golongan bahaviorisme lebih menekankan pada reiforcment positif ${ }^{43}$. Penulis juga sepakat dengan Anas bahwa pemberian hukuman perlu memperhatikan kondisi psikologis peserta didik sehingga pendidik mampu memberikan hukuman yang sesuai dengan kondisi anak ${ }^{44}$.

\section{KESIMPULAN}

Kesimpulan yang dapat diambil dari fakta dan hasil temuan, lalu pembahasan peneliti dalam penelitian ini mengenai reward dan punishment adalah: 1) Pemberian reward dan punishment sangatlah penting. Reward diberikan kepada siswa agar siswa termotivasi lagi dan agar dirinya merasa dihargai. Sedangkan punishmet diberikan agar memberikan efek jera terhadap siswa yang melakukan kesalahan sehingga siswa tersebut tidak mengulangi kesalahan yang serupa. 2) Pemberian punishment (sanksi/hukuman) haruslah yang bersifat mendidik ke arah yang positif. 3) Pemberian reward guru/kepala madrasah MAN 2 Model Medan lebih condong diapresiasikan terhadap siswa yang berprestasi di luar sekolah dengan membawa nama atau atribut madrasah. Sedangan terhadap siswa yang disiplin mentaati peraturan madrasah, kurang diapresiasikan dengan pemberian reward. 4) Ada beberapa pemberian punishment (hukuman) guru terhadap siswa yang tidak disiplin mentaati peraturan madrasah, diantaranya: Membaca al-Quran, Menghafal Hadist, Membersihkan pekarangan depan kelas, Dan mendapatkan surat pemanggilan orangtua berupa Surat Peringatan (SP).

${ }^{41}$ Ma'arif, "Hukuman (Punishment) Dalam Perspektif Pendidikan Di Pesantren"; Rofiq, "Kedisiplinan Siswa Melalui Hukuman Dalam Perspektif Stakeholder Pendidikan."

${ }^{42}$ Ibn Khaldūn, Muqoddimah Ibnu Khaldun, trans. oleh Thoha Ahmadie, 12 (Jakarta: Pustaka Firdaus, 2014).

43 Dale H. Schunk, Learning theories: an educational perspective, 6th ed (Boston: Pearson, 2012); M. Djamal, Fenomena Kekerasan di Sekolah (Yogyakarta: Pustaka Pelajar, 2016).

${ }^{44}$ Ma`arif, "Analisis Strategi Pendidikan Karakter Melalui Hukuman Preventif." 
Candra Wijaya Dkk,

\section{REFERENSI}

Abdurrahman, Nahlawi. Ushul al Tarbiyah al-Islamiyah fi al-Baiti wal al Madrasah wal al-Mujtama. Diterjemahkan oleh Shihavuddin. Jakarta: Gunan Insani, 1995.

Abrasy, Muhammad Athiya. Dasar dasar Pendidikan Islam. Diterjemahkan oleh Tasirun Sulaiman. Ponorogo: Pusat Studi Ilmu dan Amal, 1991.

Abu Thayyib, Muhammad Syamsul Haq. A'unul Ma'bud, Syarah Sunan Abu Daud,. Vol. 2. Lebanon: Dar al Fikri, 2006.

Al Munawar, Said Aqil Husin, dan Abdul Halim. Fikih bubungan antar agama. Jakarta: Ciputat Press, 2003.

Baharun, Hasan. "Penerapan pembelajaran active learning untuk meningkatkan hasil belajar siswa di madrasah.” PEDAGOGIK: Jurnal Pendidikan 1, no. 1 (2015).

Burhanddin. Wawancara, 2019.

Echols, John M., dan Hassan Shadily. An English-Indonesian Dictionary. Ithaca: Cornell University Press, 1975.

Fuad Abdul Baqi`. Mu'jam al-Muafarras. 2 ed. Beirut Lebanon: Dar al-Kotob Al-Ilmiyah, 2010.

Idi, Abdullah, dan Ahmad Jamin. "Penerapan Non-Corporal Punishment di Madrasah Aliyah: Studi Kasus di MAN 1 Sungai Penuh dan MAN Kemantan,” 2018.

Indonesien, dan Pusat Bahasa (Indonesia), ed. Kamus besar bahasa Indonesia Pusat Bahasa: Edisi Keempat. Cetakan ketujuh Edisi 4. Jakarta: Gramedia Pustaka Utama, 2013.

James, W. The Varieties of Religious Experience: A Study in Human Nature: Being the Gifford Lectures on Natural Religion Delivered at Edinburgh in 1901-1902. Creative Media Partners, LLC, 2018.

John W, Santrock. Psikologi Pendidikan. Diterjemahkan oleh Tri Wibowo BS. 6 ed. Jakarta: Prenada Media Grup, 2015.

Kelishadroky, Ahmadreza Fatahian, Ali Shamsi, Mohmadreza Bagheri, BehrozShahmirzayi, dan Mojtaba Mansorihasanabadi. "The Role of Reward and Punishment in Learning." International Journal of Advanced Biotechnology and Research 7, no. special issue (1 Maret 2016): 780-88.

Khaldūn, Ibn. Muqoddimah Ibnu Khaldun. Diterjemahkan oleh Thoha Ahmadie. 12. Jakarta: Pustaka Firdaus, 2014. 
Persepsi Guru Tentang Reward and Punisment,..

Leavy, Brian. "Effective leadership today - character not just competence." Strategy \& Leadership 44, no. 1 (11 Januari 2016): 20-29. https://doi.org/10.1108/SL-11-20150081.

Lexy J, Moloeng. Metodologi penelitian Kualitatif. 29 ed. Bandung: Rosdakarya, 2011.

M. Djamal. Fenomena Kekerasan di Sekolah. Yogyakarta: Pustaka Pelajar, 2016.

Ma`arif, Muhammad Anas. "Analisis Strategi Pendidikan Karakter Melalui Hukuman Preventif." Ta'allum: Jurnal Pendidikan Islam 6, no. 1 (6 Maret 2018): 31-56. https://doi.org/10.21274/taalum.2018.6.1.31-56.

Ma`arif, Muhammad Anas, dan Ari Kartiko. "Fenomenologi Hukuman di Pesantren : Analisis Tata Tertib Santri Pondok Pesantren Daruttaqwa Gresik.” Nadwa 12, no. 1 (22 Juni 2018): 181-96. https://doi.org/10.21580/nw.2018.12.1.1862.

Ma'arif, Muhammad Anas. "Hukuman (Punishment) Dalam Perspektif Pendidikan Di Pesantren." Ta'allum: Jurnal Pendidikan Islam 5, no. 1 (1 Juni 2017): 1-20. https://doi.org/10.21274/taalum.2017.5.1.1-20.

Malik, Fajar. Holistika Pemikiran Pendidikan. Jakarta: Raja Grafindo Persada, 2005.

Mas'ud, Abdurrachman. Menggagas format pendidikan nondikotomik: bumanisme religius sebagai paradigma pendidikan Islam. Gama Media, 2002.

Misriyah, Siti. "Implementation and Implication of Reward and Punishment Toward Character Education at Senior High School in Pemalang." Hikmatuna: Journal for Integrative Islamic Studies 1, no. 1 (2015). http://e-journal.stainpekalongan.ac.id/index.php/hikmatuna/article/view/473.

Ngalim, Purwanto. Ilmu Pendidikan Teoritis dan Praktis. 17 ed. Bandung: Remaja Rosdakarya, 2006.

Novitasari, Annisa. "Pemberian Reward and Punishment Dalam Membentuk Karakter Disiplin Anak Pada Sekolah Madrasah Ibtidaiyah." Halaqa: Islamic Education Journal 3, no. 1 (25 Mei 2019): 27-33-33. https://doi.org/10.21070/halaqa.v3i1.2113.

Purwanto, Johanes Purwanto. "Upaya Meningkatkan Disiplin Guru Dalam Kehadiran Mengajar Di Kelas Melalui Reward and Punishment Di Sdn Bandulan 1 Kecamatan Sukun Malang." Jurnal Bidang Pendidikan Dasar 1, no. 2 (10 Juni 2017): 58-69. https://doi.org/10.21067/jbpd.v1i2.1903.

Rasyidin, Al. Falsafah Pendidikan Islami. Perdana Publishing, 2008. 
Candra Wijaya Dkk,

Rofiq, Muhammad Husnur. "Kedisiplinan Siswa Melalui Hukuman Dalam Perspektif Stakeholder Pendidikan." Nidhomul Haq: Jurnal Manajemen Pendidikan Islam 2, no. 2 (2017): 82-94. https://doi.org/10.31538/ndh.v2i2.25.

Sarjana, Sri. "Education Reward for Teacher: Implementation Strategy to Improve Teacher' Performance." TARBIY A: Journal of Education in Muslim Society 3, no. 2 (29 Desember 2016): 205-17. https://doi.org/10.15408/tjems.v3i2.4390.

Schunk, Dale H. Learning theories: an educational perspective. 6th ed. Boston: Pearson, 2012.

Tafsir, Ahmad. Ilmu pendidikan Islami. Cet. 1. Bandung: Remaja Rosdakarya, 2012.

Tjipta Susana, Familia, dan Tim Pustaka. Mempertimbangan Hukuman Pada Anak. Jogjakarta: Kanisius, 2007.

Ulwan, 'Abd Allah Nasih, Muhammad Kamal al-Din 'Abd al-Ghani, Muhammad al-Shahhat Jindi, 'Ali 'Ali Ahmad Sha'ban, Muhammad Mahmud Ghali, dan Ahmad Shafiq Khatib. Pendidikan Anak Dalam Islam. Diterjemahkan oleh Jamaluddin Miri. Jakarta: Pustaka Amani, 2007.

Windari, Rusmilawati. "Penggunaan Hukum Disiplin (Corporal Punishment) pada Anak Di Lingkungan Sekolah Dalam Perspektif Hukum Pidana di Indonesia." Jurnal Hukum PRIORIS 4, no. 3 (18 Mei 2016): 303-28.

Yunus, M. Kamus Arab-Indonesia. Jakarta: Yayasan Penyelenggara Penterjemah Pentafsiran AlQuran, 1973. https://books.google.co.id/books?id=ifaNngEACAAJ.

Yusnita, Yeni, Fitri Eriyanti, Engkizar Engkizar, Fuady Anwar, Nofrina Eka Putri, Zainul Arifin, dan Syafrimen Syafril. "The Effect of Professional Education and Training for Teachers (PLPG) in Improving Pedagogic Competence and Teacher Performance." Tadris: Jurnal Keguruan dan Ilmu Tarbiyah 3, no. 2 (28 Desember 2018): 123-30. https://doi.org/10.24042/tadris.v3i2.2701.

Zuraidah. Wawancara, Guru Bimbinga Konseling, 2019. 